\title{
Diurnal regulation of the floral scent emission by light and circadian rhythm in the Phalaenopsis orchids
}

\author{
Yu-Chen Chuang ${ }^{1 \dagger}$, Ming-Chi Lee ${ }^{1 \dagger}$, Ya-Lan Chang ${ }^{1}$, Wen-Huei Chen ${ }^{2}$ and Hong-Hwa Chen ${ }^{1,2^{*}}$
}

\begin{abstract}
Background: Phalaenopsis bellina and its closely related species, P. violacea, emit linalool, geraniol and their derivatives as the predominant monoterpenes at the full-bloom stages. Geranyl diphosphate synthase (PbGDPS) is the key enzyme that converts precursors for monoterpene biosynthesis. Besides the monoterpenes being synthesized in concert with floral development stages, we noticed that the scent emission of $P$. bellina and P. violacea was detected mainly in the daytime.

Results: The monoterpenes of $P$. violacea flowers displayed a diurnal emission pattern, which was regulated by an internal oscillator in the treatment of constant light. In contrast, constant dark diminished the scent emission levels, indicating that light also affects monoterpene emission in $P$. violacea. Further treating $P$. violacea with various light wavelengths showed that the monoterpene emission was greatest in white light condition. Other Phalaenopsis hybrids, including P. I-Hsin Venus 'KHM2212' and P. Meidarland Bellina Age 'LM128', responded differently to various light wavelengths but most of them still showed the highest scent emission under the whole spectra of light. A great number of light-responsive, HY5-interacting, and circadian-responsive elements was enriched on the promoters of both structural genes and transcription factors for monoterpene biosynthesis. Furthermore, several putative genes encoding components involved in light and circadian signaling pathways were also identified in the transcriptome of P. bellina flowers at consecutive stages (from the anthesis day to day 7 post anthesis).

Conclusions: Taken together, both circadian clock and light factors had positive effects on orchid floral scent emission, and the regulation resided on the control of both structural genes and transcription factors for monoterpene biosynthesis.
\end{abstract}

Keywords: Circadian clock, Floral scent, Light-regulated, Monoterpene, Phalaenopsis

\section{Background}

Floral scent is an important factor to attract pollinators for reproduction. To achieve this, the floral scent is often developmentally and rhythmically regulated to be associated with the activity of corresponding pollinators (Muhlemann et al. 2014). As insect pollinators exhibit rhythmic activities (Saunders 1997), the flowers emit scent on specific timing in a day (Hoballah et al. 2005;

\footnotetext{
*Correspondence: hhchen@mail.ncku.edu.tw

${ }^{\dagger}$ Yu-Chen Chuang and Ming-Chi Lee contributed equally to this work

1 Department of Life Sciences, National Cheng Kung University,

Tainan 701, Taiwan

Full list of author information is available at the end of the article
}

Fenske and Imaizumi 2016). This diurnal/nocturnal emission is proposed to be regulated by a circadian clock.

The circadian clock implicates an endogenous oscillator so as to control its downstream physiological process rhythmically even under constant condition. The oscillator is established by synchronizing to the environment stimuli including light and temperature; the two factors change extremely during day/night cycle (Devlin and Kay 2000). The light receptors are responsible for inputting the light signal into the circadian clock (McClung 2006).

Light directly affects floral scent emission as well. Plants treated with various light intensities and light wavelengths show fluctuation changes of their volatiles. 
2-Phenylethanol from petunia flowers is increased under red and far-red light treatments (Colquhoun et al. 2013; Abe et al. 2003). Chiloglottone production in Chiloglottis orchids require UV-B light (Falara et al. 2012). The volatiles emitted from tea leaves are raised by blue light and red light (Fu et al. 2015).

Phalaenopsis bellina and its genetically as well as morphologically related species, $P$. violacea (Tsai 2003), are usually used in the breeding of scented cultivars. There are approximately 730 Phalaenopsis hybrids with $P$. bellina or $P$. violacea as parents registered in The Royal Horticultural Society. The floral scent profiles of $P$. bellin $a$ are dictated by monoterpenes, including linalool and geraniol and their derivatives (Hsiao et al. 2006). Geranyl diphosphate synthase of $P$. bellina (PbGDPS) is the key enzyme to supply geranyl diphosphate (GDP) for monoterpene biosynthesis. Its maximal expression is concomitant with the peak emission of monoterpenes at the full-bloom stage (day 5 post anthesis, $\mathrm{D}+5)(\mathrm{H}$ siao et al. 2008). Expression of PbGDPS and its downstream putative monoterpene synthases, TERPENE SYNTHASE 5 (PbTPS5) and PbTPS10, are regulated during flower development by several transcription factors (TFs), including PbbHLH4, PbbHLH6, PbbZIP4, PbERF1, PbERF9, and PbNAC1 (Chuang et al. unpublished).

We noticed that floral scent of $P$. bellina and $P$. violacea showed a pattern of diurnal emission in summer. The emission levels were reduced under cloudy and rainy days, even at full blooming stages, prompting us to investigate whether light or circadian rhythm plays an important role in the production of floral scent in orchids. In addition, the proposed components involved in the signal pathway were discussed as well.

\section{Methods}

\section{Plant materials and growth condition}

Two native species of Phalaenopsis orchids, P. bellina and $P$. violacea were obtained from Han-Lin Orchids (Tainan, Taiwan). Two commercial cultivars were also included in the analysis. $P$. I-Hsin Venus 'KHM221' (abbreviated as 'KHM221' in the following) is derived from a cross between 'P. I-Hsin Viola Tris' and 'P. Dragon's Gold' from I-Hsin Biotechnology Co. (Chiayi, Taiwan). The other cultivar, $P$. Meidarland Bellina Age 'LM128' (abbreviated as 'LM128' in the following) is derived from a cross between 'P. K. S. Happy Eagle' and P. bellina from Meidarland Orchids (Tainan, Taiwan). The genetic constitution of both cultivars was downloaded from ORCHIDEYA.CA (http://www.orchideya.ca/) as follows: 'KHM221'-P. amboinensis (25\%), P. equestris (25\%), P. venosa (18.75\%), P. violacea (15.63\%), P. rimestadiana (5.71\%), P. amabilis (4.69\%), P. lueddemanniana (3.13\%), and P. aphrodite (2.1\%). For 'LM128', the parenthood is the following $-P$. bellina (50\%), P. violacea (24.22\%), P. venosa (15.63\%), P. amboinensis (3.91\%), P. lueddemanniana (3.13\%), and P. micholitzii (3.13\%). Among these native Phalaenopsis orchids, several are scented Phalaenopsis, including $P$. amboinensis, $P$. bellina, $P$. lueddemanniana, $P$. venosa, and $P$. violacea. All Phalaenopsis plants were grown in the greenhouse at National Cheng Kung University (NCKU) under natural light around $100 \mu \mathrm{mol} \mathrm{m}{ }^{-2} \mathrm{~s}^{-1}$ (LI-COR photometer, United States) and controlled day/night temperature $30{ }^{\circ} \mathrm{C} / 28{ }^{\circ} \mathrm{C}$ with $80 \%$ humidity in summer.

\section{Light treatments}

Plants were transferred to the growth chamber (F180 LED, Hi Point Corporation, Taiwan) on the day of anthesis (Dd). P. violacea was first analyzed by long day $(16 \mathrm{~h} / 8 \mathrm{~h}$ light/dark (L/D) or short day condition $(8 \mathrm{~h} / 16 \mathrm{~h}$ $\mathrm{L} / \mathrm{D})$. For analyzing whether floral scent emission is regulated by circadian rhythm or by light, six plants were treated with white light $(16 \mathrm{~h} / 8 \mathrm{~h} \mathrm{~L} / \mathrm{D})$ for 4 days (from Dd to $\mathrm{D}+4$ ), and then divided into two groups under the treatment of either constant light or constant dark for the following 4 days (from $\mathrm{D}+5$ to $\mathrm{D}+8$ ). Floral scent was collected from $\mathrm{D}+4$ to $\mathrm{D}+8$ during four periods of time (from 4 a.m. to 9 a.m., 10 a.m. to 4 p.m., 4 p.m. to 9 p.m., and 10 p.m. to 4 a.m.) each day.

To study the responses of floral scent emission to various light qualities, orchid plants were treated with various light sources for $16 \mathrm{~h} / 8 \mathrm{~h} \mathrm{~L} / \mathrm{D}$ at $27^{\circ} \mathrm{C}$ with $60 \%$ humidity. Plants were domesticated for 3-5 days before harvest. LED of three-wavelengths were used, including blue light (central wavelength $450 \mathrm{~nm}$ ) at $270 \mu \mathrm{mol} \mathrm{m}^{-2} \mathrm{~s}^{-1}$, red light (central wavelength $650 \mathrm{~nm}$ ) at $30 \mu \mathrm{mol} \mathrm{m}^{-2} \mathrm{~s}^{-1}$ and farred light at $5 \mu \mathrm{mol} \mathrm{m}{ }^{-2} \mathrm{~s}^{-1}$. The scent release of $P$. violacea flowers in response to different light conditions was analyzed with triplicate biological replicates. Four individual seedling plants of 'LM128' were used and the replicate number for each condition was as the following: (a) No. 1 plant ( $n=3$ for white light (WL), $n=4$ for blue light (BL), (b) No. 2 plant ( $n=1$ for WL, $n=4$ for BL), (c) No. 3 plant ( $n=3$ for both WL and BL), and (d) No. 4 plant ( $n=3$ for WL, $n=1$ for BL) (Fig. 3). For statistical analysis between two groups, assuming equal variance, one-tailed Student's $t$ test was performed $(p<0.1)$. For 'KHM221' plants, $50 \mu \mathrm{mol} \mathrm{m}{ }^{-2} \mathrm{~s}^{-1}$ white, blue, and red light conditions, and darkness were applied with duplicates.

\section{Solid-phase extraction and GC-MS analysis}

Floral scent was collected from plants by using solidphase extraction system. The flower on the plants was placed in a plastic bag $\left(8 \times 8 \times 5 \mathrm{~cm}^{3}\right)$ inserted with a silicone tube connecting the solid phase extraction columns (DSC-Si and DCS-18, Supelco, United States) using air pumps at $350 \mathrm{mmHg}$ (Rocker, Taiwan). The volatiles 
were then eluted with the addition of hexane and identified by using (GC-MS; QP2010, SHIMADXU, Shimadzu Co, Tokyo, Japan) at the NCKU Instrument Center as previously described (Hsiao et al. 2006).

\section{Isolation of upstream regulatory fragments and cis-element prediction}

Upstream regulatory fragments of three monoterpene biosynthesis genes, including PbGDPS, PbTPS5, and PbTPS10, were isolated from $P$. bellina genomic DNA by use of the Universal GenomeWalker Kit (Clontech, USA) as previously described (Hsu et al. 2014). In addition, we also isolated $1.5-\mathrm{kb}$ upstream regulatory fragments of the identified six TFs involved in the regulation of floral monoterpene biosynthesis in $P$. bellina (Chuang et al. unpublished) from $P$. equestris genomic sequences (Cai et al. 2015). The cis-elements related to light signaling and circadian clock on the upstream regulatory fragments of both monoterpene biosynthesis genes and TFs were predicted by using PlantPAN (Chow et al. 2015). The predicted results with $100 \%$ similar score were accepted.

\section{Identification of genes involved in light and circadian clock signaling pathways}

The $P$. bellina transcriptomic data of four floral development stages (Dd, D + 3, D + 5 and D +7 ) were constructed, analyzed and annotated as described (Chuang et al. unpublished). The homologous genes of the Arabidopsis factors involved in light and circadian clock signaling pathways were identified in the P. bellina transcriptome according to $\mathrm{Nr}$ annotation. These included PHYTOCHROME A (PHYA), PHYTOCHROME B (PHYB), CRYPTOCHROME 1 (CRY1), CRYPTOCHROME 2 (CRY2), PHOTOTROPIN 1 (PHOT1), PHOT2, CONSTITUTIVE PHOTOMORPHOGENIC 1 (COP1), SUPPRESSOR OF PHYTOCHROME A1 (SPA1), PHYTOCHROME AND FLOWERING TIME 1 (PFT1), PHYTOCHROME-INTERACTING FACTOR 3 (PIF3), PIF7, HY5 (LONG HYPOCOTYL5), HY5-HOMOLOG (HYH), LATE ELONGATED HYPOCOTYL (LHY), CIRCADIAN CLOCK-ASSOCIATED 1 (CCA1), TIMING OF CAB EXPRESSION 1 (TOC1), and GIGANTEA (GI). The expression level of each individual gene in the transcriptomic data was determined by the log2 of fragments per kilobyte per million reads (FPKM) values. PHOT2, PFT1, PIF7, and TOC1 were excluded for final analysis since little or no expression for the four genes was detected.

\section{Results}

\section{Effects of light on $P$. violacea scent emission}

To determine how orchid floral scent emission varied throughout the day, $P$. violacea plants were first transferred to a $16 \mathrm{~h} / 8 \mathrm{~h} \mathrm{~L} / \mathrm{D}$ condition on $\mathrm{Dd}$ and grown under this photoperiod for 5 days. The floral scent of $P$. violacea was then collected at a 5-6-h interval on D +4 . Monoterpene emission increased at 4:00 a.m. to 10:00 a.m. internal, reached a peak at 10:00 a.m. to 16:00 p.m. interval, decreased thereafter, and was undetectable at midnight (Fig. 1a, b). These results indicate a diurnal monoterpene emission of $P$. violacea flowers.

To investigate whether the floral monoterpene emission is regulated by an internal oscillator, plants were further treated with constant light or constant dark conditions over 4 days $(\mathrm{D}+5$ to $\mathrm{D}+8)$. Previously, monoterpene biosynthesis is found to be developmentally regulated (Hsiao et al. 2008). Indeed, the monoterpene emission levels increased and peaked on $\mathrm{D}+5$ during daytime (Fig. 1a). Under constant light, although the periodical peaks were gradually decreased from $\mathrm{D}+6$ to $\mathrm{D}+8$, they did exhibit a regular and similar pattern during the rest of the photoperiod, indicating the monoterpene emission is under rhythmic regulation (Fig. 1a). In contrast, monoterpene emission decreased significantly as the plants were placed in the constant dark (Fig. 1b). A minor peak of monoterpene emission (approximately one tenth of the level in the constant light condition) was still observed at the 10:00 a.m. to 16:00 p.m. internal on $\mathrm{D}+5$ (Fig. $1 \mathrm{~b}$ ), and the emission shifted to the $4: 00$ a.m. to 10:00 a.m. interval on $D+6$, and even shifted to the midnight interval on $\mathrm{D}+7$ and $\mathrm{D}+8$ (Fig. 1b). The above results indicate a circadian regulation of floral monoterpene emission, and the effect of light as well.

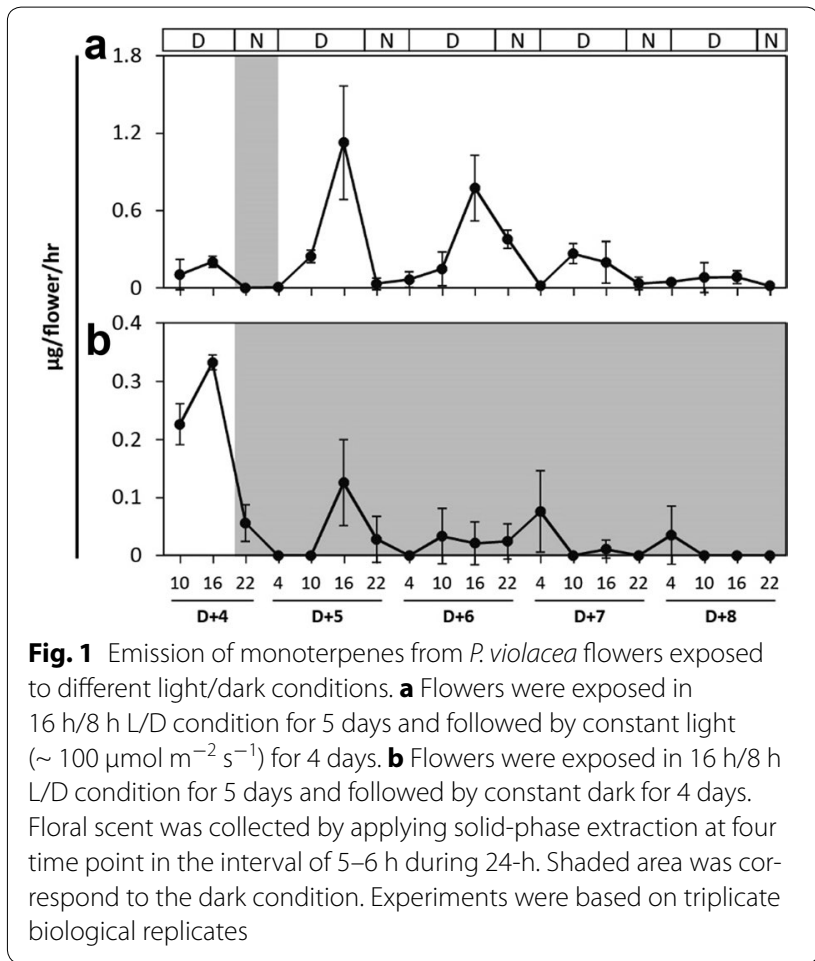


Effects of various light qualities on monoterpene emission To determine how the light quality could affect the orchid floral scent emission, we treated plants with various light wavelengths. Naturally, P. violacea is a native species in Malaysia and blooms in summer, and is considered as a long-day plant. Actually, the short-day condition $(8 \mathrm{~h} / 16 \mathrm{~h} \mathrm{~L} / \mathrm{D})$ reduced the floral monoterpene emission (Fig. 2). Therefore, we treated the orchids in the longday condition $(16 \mathrm{~h} / 8 \mathrm{~h} \mathrm{~L} / \mathrm{D})$ with specified wavelengths, including the white light, blue light $\left(270 \mu \mathrm{mol} \mathrm{m}^{-2} \mathrm{~s}^{-1}\right)$, red light $\left(30 \mu \mathrm{mol} \mathrm{m}^{-2} \mathrm{~s}^{-1}\right)$, far-red light $\left(5 \mu \mathrm{mol} \mathrm{m}^{-2} \mathrm{~s}^{-1}\right)$ and darkness. The emission of linalool and geraniol was higher under white light than those under the other light spectra for P. violacea (Fig. 2). Among them, blue light, far-red light and dark had more effects than red light on the monoterpene emission. In contrast to linalool, the emission of geraniol nearly diminished under far-redlight and dark treatment in $P$. violacea.

To see whether the offspring of $P$. violacea exhibits the similar response to different light treatment as their ancestor, we then analyzed the responses of two commercial Phalaenopsis cultivars containing $P$. violacea background to the light spectra. One is 'KHM2212' whose ancestry contains $15.63 \%$ of $P$. violacea. 'KHM2212' plants were basically with identical genetic background since they are micropropagated in tissue culture and their responses to different light were consistent (Fig. 3). 'KHM2212' emitted linalool and eucalyptol, and the emission of linalool was higher under white-light treatment than all the other light spectra (Fig. 3), similar to the observation in P. violacea (Fig. 2). The difference was that the red-light treatment reduced the emission of linalool more significantly than blue light and darkness in 'KHM2212' (Fig. 3). In addition, those various light spectra had little effect on the emissions of eucalyptol (Fig. 3),

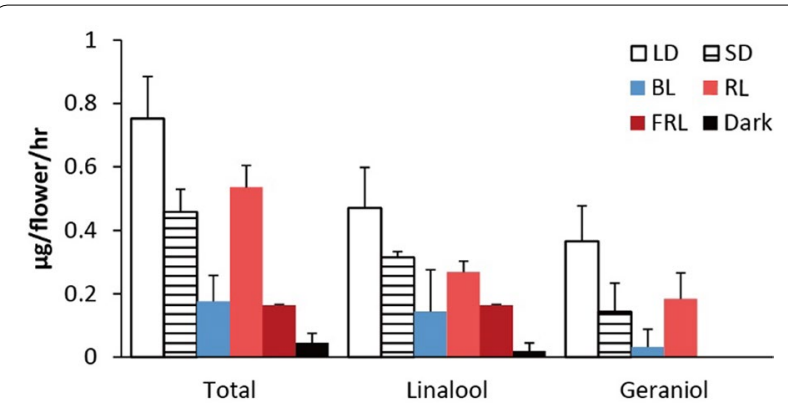

Fig. 2 Emission of monoterpenes from $P$. violacea flowers in different light condition. The plants were treated with $100 \mu \mathrm{mol} \mathrm{m} \mathrm{m}^{-2} \mathrm{~s}^{-1}$ white light in long day ( $18 \mathrm{~h} / 6 \mathrm{~h} \mathrm{~L} / \mathrm{D}, \mathrm{LD})$ and short day $(6 \mathrm{~h} / 18 \mathrm{~h} \mathrm{L/D}, \mathrm{SD})$ conditions, $270 \mu \mathrm{mol} \mathrm{m} \mathrm{m}^{-2} \mathrm{~s}^{-1}$ blue light (BL), $30 \mu \mathrm{mol} \mathrm{m} \mathrm{m}^{-2} \mathrm{~s}^{-1}$ red light (RL), $5 \mu \mathrm{mol} \mathrm{m} \mathrm{m}^{-2} \mathrm{~s}^{-1}$ far-red light (FRL), and darkness (dark). Scent was collected on $\mathrm{D}+5$ of an individual $P$. violacea flower. Experiments were based on triplicate biological replicates

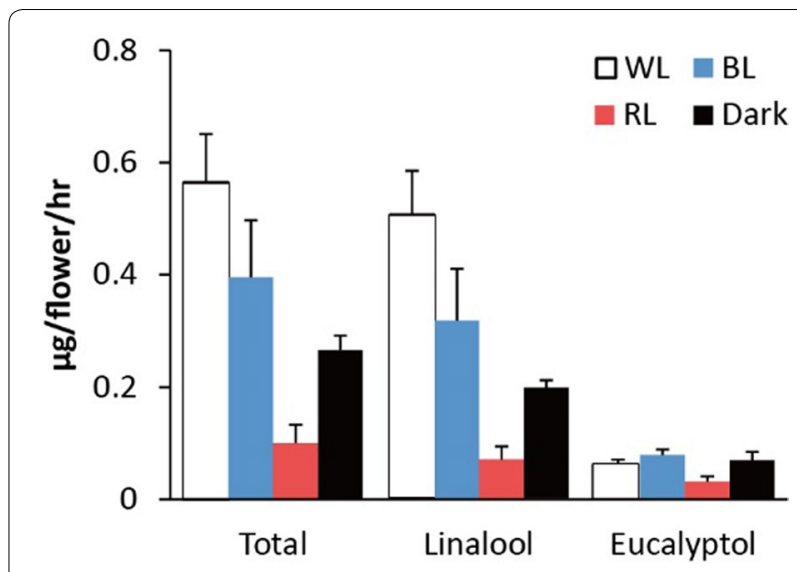

Fig. 3 Emission of monoterpenes from P. I-Hsin Venus 'KHM2212' in different light conditions. The plants were treated with $50 \mu \mathrm{mol} \mathrm{m} \mathrm{m}^{-2} \mathrm{~s}^{-1}$ white (WL), red (RL), and blue (BL) light conditions, and darkness (dark). Scent was collected from six flowers on D +5 . Experiments were based on duplicate biological replicates

a compound not detected in the volatile profile of $P$. violacea. We deduced that the differences might be resulted from the genetic constitution of 'KHM2212' other than $P$. violacea.

Another Phalaenopsis hybrid examined was 'LM128' containing the ancestry of P. bellina (50\%) and P. violacea (24.22\%). 'LM128' is an orchid hybrid generated from at least seven generations of breeding and six native species were involved, leading to its complicated genetic background. We selected four 'LM128' seedlings plants derived from independent lines and found that the floral scent emission for each individual plant responded differentially to white-light and blue-light conditions (Fig. 4). Among them, two plants showed similar responses to both light spectra as $P$. violacea, in which blue-light treatment reduced the scent emission (Fig. 4a, b). The other two responded differently, one seedling emitted higher monoterpene under blue light than white light (Fig. 4c) and the other showed the same level of emission (Fig. 4d). Although the responses were different among the four plants, the reactions of linalool and geraniol emission to both light spectra were consistent in each 'LM128' individual (Fig. 4).

Together, these results imply that whole spectra of light (i.e. white light) is conferred the optimal emission of scent compounds in most Phalaenopsis orchids with $P$. violacea background.

\section{Analysis of the upstream regulatory fragments} of structural genes and TFs for monoterpene biosynthesis In the light signaling pathway, HY5 binds to the promoters of early light-responsive genes and TF genes to regulate plant development and photomorphogenesis (Lee 

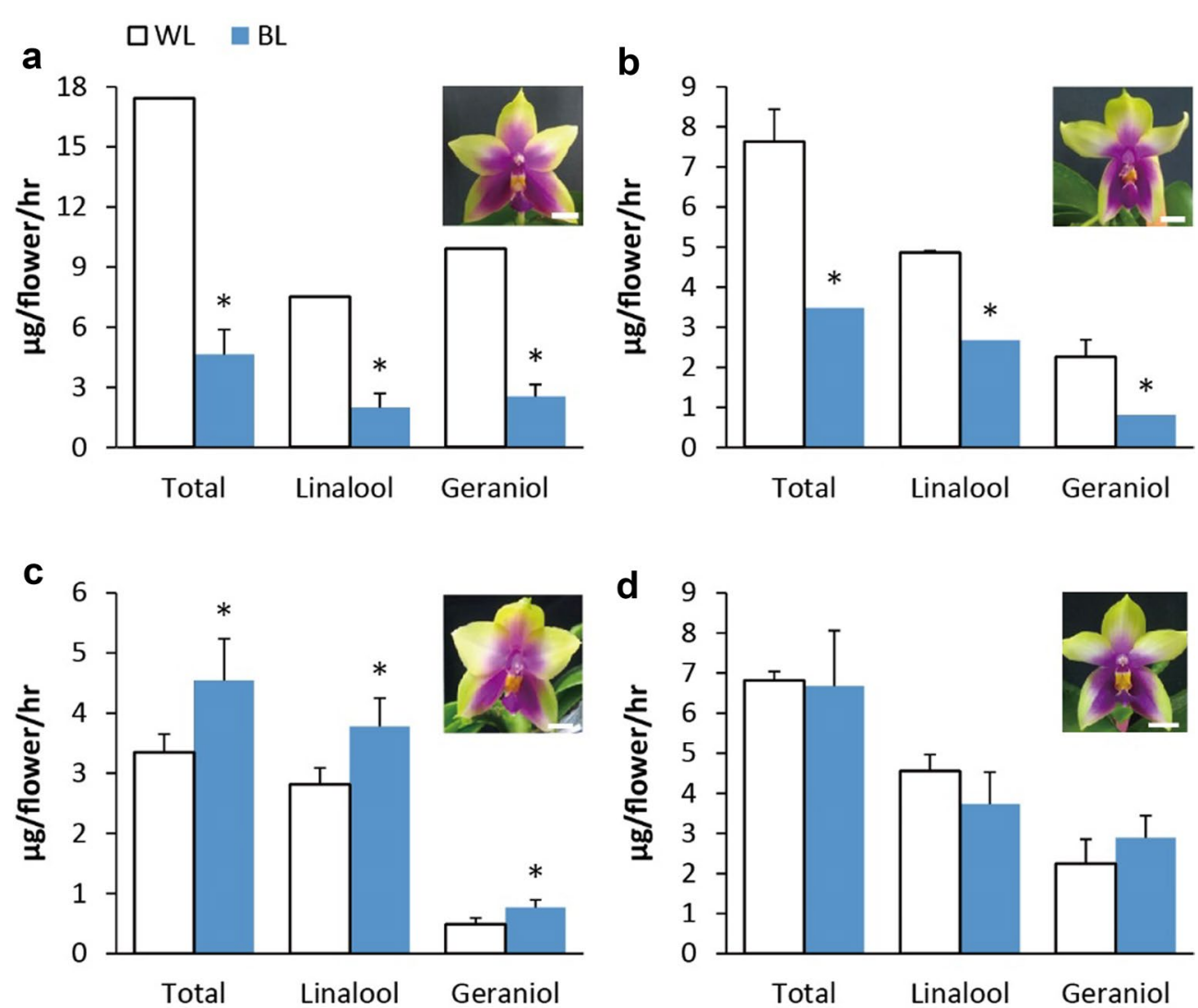

Fig. 4 Emission of monoterpenes of four individual plants of P. Meidarland Bellina Age 'LM128'. The plants were treated with $100 \mu \mathrm{mol} \mathrm{m} \mathrm{m}^{-2} \mathrm{~s}^{-1}$ white light (WL), and $270 \mu \mathrm{mol} \mathrm{m} \mathrm{s}^{-1}$ blue light (BL) conditions. The replicate number for each plants was listed as following: a No. 1 plant: $n=3$ for white light (WL), and $n=4$ for blue light (BL). b No. 2 plant: $n=1$ for WL, and $n=4$ for BL. c No. 3 plant: $n=3$ for both WL and BL. d No. 4 plant: $n=3$ for WL, and $n=1$ for BL. Different letters on the column indicate significant difference by Student's $t$ test ( $p$ value $<0.1)$. Scale bar $=1 \mathrm{~cm}$

et al. 2007). We examined whether the upstream promoters of the structural genes and TFs for monoterpene biosynthesis in Phalaenopsis contain any HY5-interacting ACGT-containing elements (ACEs), such as C-box (GACGTC), Z-box (ATACGGT), CA-hybrid (GACGTA), CG-hybrid (GACGTG), as well as G-box (CACGTG) for PIF recognition (Lee et al. 2007; Zhang et al. 2011). Among the genes analyzed, PbNAC1 contained a large number of ACE motifs $(n=7)$, implying that it might be a target of HY5 protein (Table 1, Fig. 5). In addition, several other cis-acting elements related to light and circadian clock signaling were also identified in the $1.5-\mathrm{kb}$ promoter of PbNAC1 by using PlantPAN (Chow et al. 2015). These included GATA-box (Luo et al. 2010), GT1motif (Zhou 1999), and evening elements (EE) for CCA1 and LHY interaction (Alabadí et al. 2001) (Table 1, Fig. 5). These cis-elements were identified in the promoter of structural genes and TFs for monoterpene biosynthesis as well, although in a smaller number (Table 1, Fig. 5). PbGDPS, a key enzyme in the monoterpene biosynthesis (Hsiao et al. 2008), was the only one structural gene containing EEs, suggesting that it might be a downstream gene of circadian clock pathway.

\section{Identification of factors involved in light and circadian clock signaling pathways}

Both light and circadian signaling pathways were well studied in Arabidopsis (Dodd et al. 2015; Lau and Deng 2012). We identified their homologous genes in P. bellina floral transcriptome to explore the candidate factors responsible for the circadian- and light-regulating scent emission in Phalaenopsis flowers. The transcriptomic data were constructed from four floral developmental stages, including Dd, D $+3, \mathrm{D}+5$ and $\mathrm{D}+7$ (Chuang et al. unpublished). The expression levels of the homologous genes were determined by $\log 2$ of FPKM values, and compared to that of PbGDPS (Fig. 6). The putative genes encoding the factors involved in light and circadian signaling pathways were successfully isolated in P. bellina transcriptome, and several ones showed higher expression, including putative genes encoding PHYTOCHROME A, PHYTOCHROME B, CRYPTOCHROME 2, COP1, LHY, 
Table 1 cis-elements on the promoter fragments of scent-related structural genes and TFs

\begin{tabular}{|c|c|c|c|c|c|c|c|c|c|}
\hline \multirow[t]{3}{*}{ Gene name } & \multirow[t]{3}{*}{ Promoter length } & \multicolumn{5}{|c|}{ HY5 interaction } & \multicolumn{2}{|c|}{ Light-responsive } & \multirow{3}{*}{$\begin{array}{l}\text { Circadian } \\
\text { EE }\end{array}$} \\
\hline & & \multirow[t]{2}{*}{ C-box ${ }^{a}$} & \multirow[t]{2}{*}{ Z-box } & \multirow[t]{2}{*}{ G-box ${ }^{a}$} & \multirow{2}{*}{$\begin{array}{l}\text { CA } \\
\text { Hybrid }\end{array}$} & CG & GATA & GT1-motif & \\
\hline & & & & & & Hybrid & & & \\
\hline PbGDPSp & 1077 & $-{ }^{\mathrm{b}}$ & - & - & - & - & 3 & 1 & 2 \\
\hline PbTPS5p & 1161 & - & - & - & - & - & - & - & - \\
\hline PbTPS1Op & 1506 & 1 & - & - & - & - & 3 & - & - \\
\hline PebHLH4p & 1538 & - & - & - & - & 1 & 2 & 1 & - \\
\hline PebHLH6p & 1673 & - & - & 1 & - & - & 2 & 1 & - \\
\hline PebZIP4p & 1537 & - & - & - & 1 & 1 & - & - & - \\
\hline PeERF1p & 1500 & - & - & - & - & - & 1 & - & - \\
\hline PeERF9p & 1565 & - & - & - & 1 & 1 & - & - & 2 \\
\hline PENAC1p & 1501 & 1 & 2 & 1 & - & 3 & 3 & 2 & 1 \\
\hline
\end{tabular}

a The number of palindromic sequences was counted by the sense strand

b The dash indicates that the cis-element is not detected

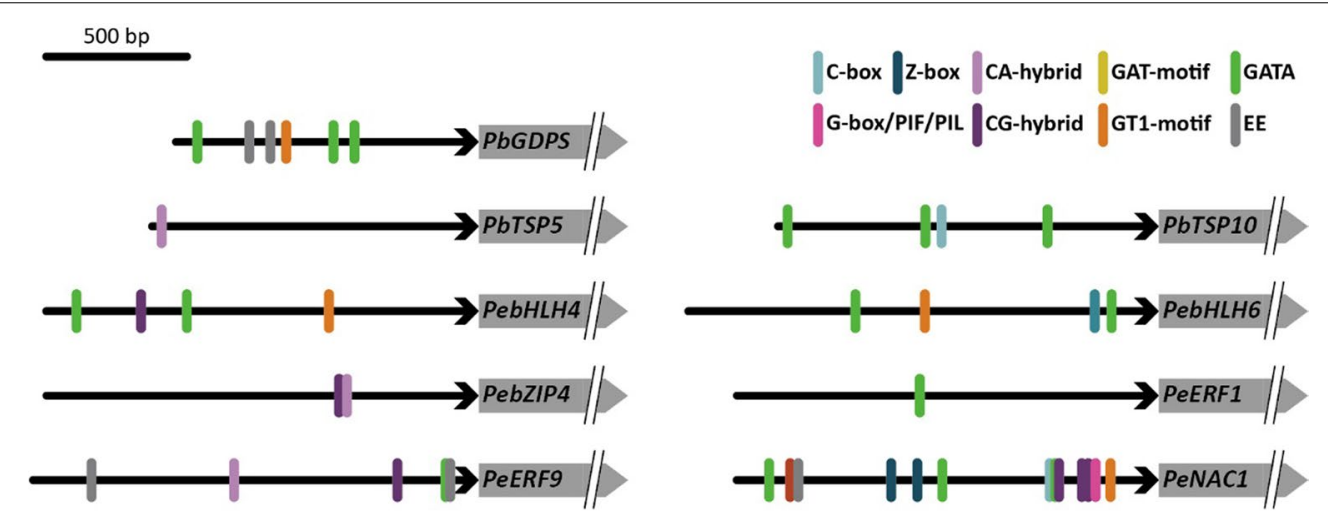

Fig. 5 Light- and circadian-responsive elements on the upstream regulatory fragments of three structural genes and six transcription factors for floral monoterpene biosynthesis in P. bellina. The distinct cis-elements on each fragments were represented by their location predicted by PlantPAN (Chow et al. 2015). The gene length was not shown in proportion to actual length. Scale bar of upstream regulatory fragments $=500 \mathrm{bp}$

CCA1, HY5 and GI (Fig. 6). As we identified the cis-elements related to the light and circadian responses in the structural genes and TFs for monoterpene biosynthesis, it is worth to study the function of these putative genes in Phalaenopsis orchids in the future.

\section{Discussion}

Light and/or circadian rhythm regulation on the emission of monoterpenes

Phalaenopsis bellina, or P. violacea, emits monoterpenes during daytime and is considered as day-pollinated flowers. Here, we present that this diurnal emission is affected mainly by circadian clock and to a lesser degree by the light factor. This is different from other plant species, whose diurnal rhythm is usually regulated by a single factor. Rosa hybrida L. cv. Honesty, Antirrhinum majus, and Rosa damascena semperflorens emit monoterpenes regulated by a circadian clock regardless of the light stimulus (Helsper et al. 1998; Dudareva et al. 2003; Picone et al. 2004). In contrast, in Mahonia japonica and Rosa hybrida cv. Fragrant Cloud, the diurnal emission of monoterpenes is determined primarily by the photoperiod (Picone et al. 2002; Hendel-Rahmanim et al. 2007).

The monoterpene emission patterns are likely to be parallel the expression of structural genes. In A. majus flowers, the terpene backbone biosynthesis pathway, GDPS and monoterpene synthase are all under circadian regulation (Dudareva et al. 2003, 2005; Tholl et al. 2004). The emission of monoterpenes in P. bellina matches the expression patterns of $P b G D P S$ during flower development (Hsiao et al. 2008). Further study of whether these structural genes contribute to the diurnal emission will help to clarify how monoterpene biosynthesis is controlled in a day. 


\begin{tabular}{|c|c|c|c|c|c|c|}
\hline \multirow{3}{*}{$\begin{array}{l}\text { Dd D+3D+5D+7 } \\
\begin{array}{c}\text { Putative } \\
\text { function }\end{array}\end{array}$} & \multirow{3}{*}{$\begin{array}{l}\text { Developmental stages } \\
\text { of } P \text {. beliina flowers }\end{array}$} & \multirow{3}{*}{$\begin{array}{c}0 \\
\text { Gene Name }\end{array}$} & \multicolumn{4}{|c|}{$\begin{array}{l}6 \text { Color scale for } \\
\text { Log2 of FPKM values }\end{array}$} \\
\hline & & & \multicolumn{4}{|c|}{ Log2 of FPKM } \\
\hline & & & $\mathrm{Dd}$ & $D+3$ & $D+5$ & $D+7$ \\
\hline \multicolumn{7}{|l|}{ Photoreceptors } \\
\hline \multirow{2}{*}{ Phytochrome A } & CL6189.Contig1_All & PhyA-1 & & & & \\
\hline & CL6189.Contig2_All & PhyA-2 & & & & \\
\hline \multirow[t]{2}{*}{ Phytochrome B2 } & Unigene5329_All & PhyB2 & & & & \\
\hline & CL1394.Contig1_All & Cry1-1 & & & & \\
\hline \multirow[t]{2}{*}{ Cryptochrome 1} & CL4318.Contig1_All & Cry1-2 & & & & \\
\hline & CL4318.Contig2_All & Cry1-3 & & & & \\
\hline Cryptochrome 2 & Unigene11075_All & Cry2 & & & & \\
\hline \multirow{2}{*}{ Phototropin 1} & CL2817.Contig1_All & Photo1-1 & & & & \\
\hline & CL2817.Contig2_All & Photo1-2 & & & & \\
\hline \multicolumn{7}{|l|}{ Signaling center } \\
\hline COP1 & Unigene5916_All & COP1 & & & & \\
\hline \multirow{2}{*}{ SPA1 } & CL3444.Contig1_All & SPA1-1 & & & & \\
\hline & CL3444.Contig2_All & SPA1-2 & & & & \\
\hline LHY & CL1214.Contig2_All & $L H Y$ & & & & \\
\hline CCA1 & CL5470.Contig3_All & CCA1 & & & & \\
\hline \multicolumn{7}{|l|}{ Effectors } \\
\hline PIF3 & CL4122.Contig1_All & PIF3 & & & & \\
\hline \multirow{2}{*}{ HYS } & CL2226.Contig2_All & HY5-1 & & & & \\
\hline & Unigene8999_All & HY5-2 & & & & \\
\hline $\mathrm{HYH}$ & Unigene13261_All & HYH & & & & \\
\hline \multirow{2}{*}{ GI } & CL5073.Contig1_All & Gl-1 & & & & \\
\hline & CL5073.Contig2_All & $G /-2$ & & & & \\
\hline \multicolumn{7}{|l|}{ Monoterpenes } \\
\hline GDPS & Unigene5853_All & GDPS & & & & \\
\hline
\end{tabular}

Fig. 6 Expression profiles of putative genes encoding components involved in light and circadian clock signaling pathway in $P$. bellina floral transcriptomes. The gene expression levels are represented by a color gradient from red to light-red

\section{HY5 integrates the light and circadian signaling pathway for terpene biosynthesis}

HY5, a specialized basic leucine zipper (bZIP) TF, plays an important role in mastering both light and circadian signaling pathway (Gangappa and Botto 2016). The role of HY5 on terpene biosynthesis is recently unraveled. Arabidopsis responds to illumination by integrating HY5 to repress the mevalonate (MVA) pathway and activate methylerythritol phosphate (MEP) pathway to increase plastidial terpenes for photosynthesis (Rodríguez-Concepción et al. 2004). As grape berries are shaded from light (sunlight exclusion), the downregulation of the terpene biosynthesis leads to the reduction of terpene content and altered aroma (Zhang et al. 2014, 2017). HY5 might be involved in the lightinduced terpene production in grapes (Costantini et al. 2017). Moreover, HY5-binding sites are identified in the promoter regions of terpene biosynthesis genes (Lee et al. 2007). In Artemisia annua, a circadian-regulated $\beta$-pinene synthase gene, $Q H 6$, contains G-box motif to interact with HY5 for retaining rhythmic expression under constant condition (Zhou et al. 2015). Other regulator in light signaling pathway, such as PIF5, is involved in terpene biosynthesis as well (Mannen et al. 2014). Here, we identified several HY5-interacting motifs on the upstream regulatory fragments of structural genes and TFs, especially $\mathrm{PbNAC1}$, suggesting that the light and circadian clock signals might manage monoterpene biosynthesis in P. bellina by controlling these genes.

Naturally, the striking changes of light at dawn and dusk help to entrain the circadian clock. Phytochrome is responsible for the red-light input and cryptochrome for the blue-light (Devlin and Kay 2000). Our results show that $P$. violacea responded differently to various light qualities. It is intriguing to know how the signaling components isolated in this study work together to regulate monoterpene biosynthesis in Phalaenopsis orchids, including photoreceptors and COP1.

The floral scent of $P$. bellina is composed by monoterpenes and its biosynthesis is regulated by multiple factors. PbGDPS is expressed in the epidermal cells on the surface of perianth (Hsiao et al. 2008), suggesting a factor for its tissue specificity. Moreover, the development factor is involved to induce the scent biosynthesis at fullbloomed stages (Chuang et al. unpublished). In this study, we present that both circadian clock and light factor are required for the diurnal emission. These factors cooperate to establish the optimal spatial and temporal emission patterns of monoterpenes in Phalaenopsis flowers.

\section{Conclusion}

The present study indicates that the diurnal emission of monoterpenes from $P$. violacea flowers is controlled by a circadian clock and light factors. In addition, white light was the most optimal light condition to emit monoterpenes in four Phalaenopsis orchids examined. The light and circadian signal might be associate with floral monoterpene emission by regulating the transcription factors for monoterpene biosynthesis.

\section{Authors' contributions}

YCC, MCL, YLC, WHC and HHC conceived and designed the experiments. YCC, $\mathrm{MCL}$, and $\mathrm{YLC}$ performed the experiments. YCC and $\mathrm{MCL}$ analyzed the data. YCC, MCL and HHC wrote the manuscript. All authors read and approved the final manuscript.

\section{Author details}

${ }^{1}$ Department of Life Sciences, National Cheng Kung University, Tainan 701, Taiwan. ${ }^{2}$ Orchid Research and Development Center, National Cheng Kung University, Tainan 701, Taiwan.

\section{Acknowledgements}

We thank Dr. Shu-Hsing Wu (Institute of Plant and Microbial Biology, Academia Sinica, Taipei, Taiwan) for helpful discussions. We thank Dr. Chi-Kuang Wen (Shanghai Institutes for Biological Sciences, Chinese Academy of Sciences, China) for careful reading and suggestions of the manuscript. We thank Dr. 
Swee-Suak Ko (Academia Sinica Biotechnology Center in Southern Taiwan, Tainan, Taiwan) for assistance in performing experiments with their growth chamber. We thank Dr. Ming-Hsien Hsieh (Tainan District Agricultural Research and Extension Station, Council of Agriculture, Tainan, Taiwan) for kindly providing the photometer.

\section{Competing interests}

The authors declare that they have no competing interests.

\section{Availability of data and materials}

Sequence data supporting the findings of this study have been deposited in GenBank [Accession Nos. PbGDPS (EU023907)]. The RNA-seq data generated during the study are available from the corresponding author on reasonable request.

\section{Consent for publication}

Not applicable.

\section{Ethics approval and consent to participate}

Not applicable.

\section{Funding}

This work was supported by Ministry of Science and Technology, Taiwan, Grant No.: 105-2313-B-006-002-MY3.

\section{Publisher's Note}

Springer Nature remains neutral with regard to jurisdictional claims in published maps and institutional affiliations.

Received: 7 July 2017 Accepted: 9 November 2017

Published online: 15 November 2017

\section{References}

Abe H, Urao T, Ito T, Seki M, Shinozaki K, Yamaguchi-Shinozaki K (2003) Arabidopsis AtMYC2 (bHLH) and AtMYB2 (MYB) function as transcriptional activators in abscisic acid signaling. Plant Cell 15:63-78

Alabadí D, Oyama T, Yanovsky MJ, Harmon FG, Más P, Kay SA (2001) Reciprocal regulation between TOC1 and LHY/CCA1 within the Arabidopsis circadian clock. Science 293:880-883

Cai J, Liu X, Vanneste K, Proost S, Tsai WC, Liu KW, Chen LJ, He Y, Xu Q, Bian C (2015) The genome sequence of the orchid Phalaenopsis equestris. Nat Genet 47:65-72

Chow CN, Zheng HQ, Wu NY, Chien CH, Huang HD, Lee TY, Chiang-Hsieh YF, Hou PF, Yang TY, Chang WC (2015) PlantPAN 2.0: an update of plant promoter analysis navigator for reconstructing transcriptional regulatory networks in plants. Nucleic Acids Res 44:D1154-D1160

Colquhoun TA, Schwieterman ML, Gilbert JL, Jaworski EA, Langer KM, Jones CR, Rushing GV, Hunter TM, Olmstead J, Clark DG (2013) Light modulation of volatile organic compounds from petunia flowers and select fruits. Postharvest Biol Technol 86:37-44

Costantini L, Kappel CD, Trenti M, Battilana J, Emanuelli F, Sordo M, Moretto M, Camps C, Larcher R, Delrot S (2017) Drawing links from transcriptome to metabolites: the evolution of aroma in the ripening berry of Moscato Bianco (Vitis vinifera L.). Front Plant Sci 8:780

Devlin PF, Kay SA (2000) Cryptochromes are required for phytochrome signaling to the circadian clock but not for rhythmicity. Plant Cell 12:2499-2509

Dodd AN, Belbin FE, Frank A, Webb AA (2015) Interactions between circadian clocks and photosynthesis for the temporal and spatial coordination of metabolism. Front Plant Sci 6:245

Dudareva N, Martin D, Kish CM, Kolosova N, Gorenstein N, Fäldt J, Miller B, Bohlmann J (2003) (E)- $\beta$-ocimene and myrcene synthase genes of floral scent biosynthesis in snapdragon: function and expression of three terpene synthase genes of a new terpene synthase subfamily. Plant Cell 15:1227-1241

Dudareva N, Andersson S, Orlova I, Gatto N, Reichelt M, Rhodes D, Boland W, Gershenzon J (2005) The nonmevalonate pathway supports both monoterpene and sesquiterpene formation in snapdragon flowers. Proc Natl Acad Sci USA 102:933-938

Falara V, Amarasinghe R, Poldy J, Pichersky E, Barrow RA, Peakall R (2012) The production of a key floral volatile is dependent on UV light in a sexually deceptive orchid. Ann Bot 111:21-30

Fenske MP, Imaizumi T (2016) Circadian rhythms in floral scent emission. Front Plant Sci 7:462

Fu X, Chen Y, Mei X, Katsuno T, Kobayashi E, Dong F, Watanabe N, Yang Z (2015) Regulation of formation of volatile compounds of tea (Camellia sinensis) leaves by single light wavelength. Sci Rep 5:16858

Gangappa SN, Botto JF (2016) The multifaceted roles of HY5 in plant growth and development. Mol Plant 9:1353-1365

Helsper JP, Davies JA, Bouwmeester HJ, Krol AF, Van Kampen MH (1998) Circadian rhythmicity in emission of volatile compounds by flowers of Rosa hybrida L. cv. Honesty. Planta 207:88-95

Hendel-Rahmanim K, Masci T, Vainstein A, Weiss D (2007) Diurnal regulation of scent emission in rose flowers. Planta 226:1491-1499

Hoballah ME, Stuurman J, Turlings TC, Guerin PM, Connetable S, Kuhlemeier C (2005) The composition and timing of flower odour emission by wild Petunia axillaris coincide with the antennal perception and nocturnal activity of the pollinator Manduca sexta. Planta 222:141-150

Hsiao YY, Tsai WC, Kuoh CS, Huang TH, Wang HC, Wu TS, Leu YL, Chen WH, Chen HH (2006) Comparison of transcripts in Phalaenopsis bellina and Phalaenopsis equestris (Orchidaceae) flowers to deduce monoterpene biosynthesis pathway. BMC Plant Biol 6:14

Hsiao YY, Jeng MF, Tsai WC, Chuang YC, Li CY, Wu TS, Kuoh CS, Chen WH, Chen HH (2008) A novel homodimeric geranyl diphosphate synthase from the orchid Phalaenopsis bellina lacking a DD (X) 2-4D motif. Plant J 55:719-733

Hsu CC, Wu PS, Chen TC, Yu CW, Tsai WC, Wu K, Wu WL, Chen WH, Chen HH (2014) Histone acetylation accompanied with promoter sequences displaying differential expression profiles of B-class MADS-box genes for Phalaenopsis floral morphogenesis. PLoS ONE 9:e106033

Lau OS, Deng XW (2012) The photomorphogenic repressors COP1 and DET1: 20 years later. Trends Plant Sci 17:584-593

Lee J, He K, Stolc V, Lee H, Figueroa P, Gao Y, Tongprasit W, Zhao H, Lee I, Deng XW (2007) Analysis of transcription factor HY5 genomic binding sites revealed its hierarchical role in light regulation of development. Plant Cell 19:731-749

Luo XM, Lin WH, Zhu S, Zhu JY, Sun Y, Fan XY, Cheng M, Hao Y, Oh E, Tian M (2010) Integration of light-and brassinosteroid-signaling pathways by a GATA transcription factor in Arabidopsis. Dev Cell 19:872-883

Mannen K, Matsumoto T, Takahashi S, Yamaguchi Y, Tsukagoshi M, Sano R, Suzuki H, Sakurai N, Shibata D, Koyama T (2014) Coordinated transcriptional regulation of isopentenyl diphosphate biosynthetic pathway enzymes in plastids by phytochrome-interacting factor 5. Biochem Biophys Res Commun 443:768-774

Mcclung CR (2006) Plant circadian rhythms. Plant Cell 18:792-803

Muhlemann JK, Klempien A, Dudareva N (2014) Floral volatiles: from biosynthesis to function. Plant Cell Environ 37:1936-1949

Picone JM, Mactavish HS, Clery RA (2002) Emission of floral volatiles from Mahonia japonica (Berberidaceae). Phytochemistry 60:611-617

Picone JM, Clery RA, Watanabe N, Mactavish HS, Turnbull CG (2004) Rhythmic emission of floral volatiles from Rosa damascena semperflorens cv.'Quatre Saisons.' Planta 219:468-478

Rodríguez-Concepción M, Forés O, Martínez-García JF, González V, Phillips MA, Ferrer A, Boronat A (2004) Distinct light-mediated pathways regulate the biosynthesis and exchange of isoprenoid precursors during Arabidopsis seedling development. Plant Cell 16:144-156

Saunders D (1997) Insect circadian rhythms and photoperiodism. Invertebr Neurosci 3:155-164

Tholl D, Kish CM, Orlova I, Sherman D, Gershenzon J, Pichersky E, Dudareva $\mathrm{N}$ (2004) Formation of monoterpenes in Antirrhinum majus and Clarkia breweri flowers involves heterodimeric geranyl diphosphate synthases. Plant Cell 16:977-992

Tsai CC (2003) Molecular phylogeny, biogeography, and evolutionary trends of the genus Phalaenopsis (Orchidaceae). Dissertation, National Sun Yat-Sen University

Zhang H, He H, Wang X, Wang X, Yang X, Li L, Deng XW (2011) Genomewide mapping of the HY5-mediated gene networks in Arabidopsis that 
involve both transcriptional and post-transcriptional regulation. Plant J 65:346-358

Zhang H, Fan P, Liu C, Wu B, Li S, Liang Z (2014) Sunlight exclusion from Muscat grape alters volatile profiles during berry development. Food Chem 164:242-250

Zhang E, Chai F, Zhang H, Li S, Liang Z, Fan P (2017) Effects of sunlight exclusion on the profiles of monoterpene biosynthesis and accumulation in grape exocarp and mesocarp. Food Chem 237:379-389
Zhou D-X (1999) Regulatory mechanism of plant gene transcription by GTelements and GT-factors. Trends Plant Sci 4:210-214

Zhou F, Sun TH, Zhao L, Pan XW, Lu S (2015) The bZIP transcription factor HY5 interacts with the promoter of the monoterpene synthase gene QH6 in modulating its rhythmic expression. Front Plant Sci 6:304

\section{Submit your manuscript to a SpringerOpen ${ }^{\circ}$ journal and benefit from:}

- Convenient online submission

- Rigorous peer review

- Open access: articles freely available online

- High visibility within the field

- Retaining the copyright to your article

Submit your next manuscript at $\boldsymbol{\nabla}$ springeropen.com 